\title{
EXPERIMENTAL INVESTIGATION ON THE FRESH AND HARDENED PROPERTIES OF CONCRETE INCORPORATING POLYVINYL
}

\author{
Abo Dhaheer, M.S., \\ Civil Engineering Department, College of Engineering, University of Al-Qadisiyah \\ Al-Diwaniyah, Iraq \\ E mail: \\ shamelm2000@gmail.com ; mohammed.abodhaheer@qu.edu.ia
}

Received on 22 January 2018 Accepted on 24 January 2018 Published on 14 May 2018

DOI: $10.30772 / q j e s . v 11 i 1.525$

\begin{abstract}
Polyvinyl alcohol (PVA) has undergone intensive research work that has led to confidence in its utilization in various applications. Nevertheless, its utilization as a construction material in the concrete industry still needs to be fully addressed. In this paper, an experimental study was dedicated to investigate the influence of PVA on the fresh and hardened properties of concrete. Three different strength grades, represented by water to cement ratios (w/C), of 0.4, 0.5 and 0.6, with four different PVA dosages of 1 , 2,3 and $4 \%$, by mass of cement, were employed in the preparation of the concrete mixes. Concerning the fresh properties, results showed that there was a significant contribution of PVA to the workability in all produced mixes, irrespective of w/c ratio. In addition, the initial and final setting time of cement pastes modified with $2 \%$ PVA were longer than that of the control paste. In term of the hardened properties, results demonstrated that the compressive $\left(f_{c u}\right)$ and splitting tensile $\left(f_{s t}\right)$ strengths of concrete are dominated by amounts of PVA in the mix and $w / c$ ratios. With the high and moderate $w / c$ ratios, they increased when up to 2\% PVA was used, and thereafter decreased. However, with the low w/c, PVA did not provide any improvement in the strength, but instead, it decreased the strength when more than $2 \%$ was added. The findings revealed also that increasing PVA content resulted in a significant reduction in total water absorption (TWA) of concrete specimens. The larger the PVA contents the lower is the TWA of the specimens.
\end{abstract}

Keywords: polyvinyl alcohol, compressive strength, tensile strength, slump test, total water absorption

\section{INTRODUCTION}

The reason why concrete is by far one of the most widely utilized construction material is that it can be formed in preferred formwork with a superior durability, strength, ability to withstand extreme environments and in-situate fabrication. Nevertheless, being heterogeneous and porous material, plain and reinforced concrete structures could be prone to inherent defects such as voids, micro-cracks and water-filled pores [1]. 


\section{AL-QADISIYAH JOURNAL FOR ENGINEERING SCIENCES}

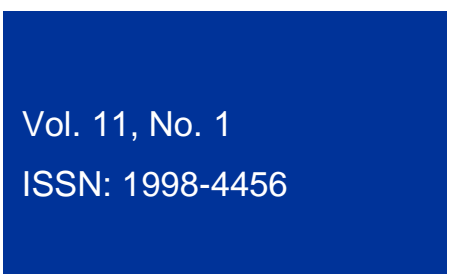

These defects, even prior to load application, can become a serious issue in the concrete structures influencing their strength and durability performance [2].

A judicious choice to overcoming or minimizing the adverse influence of the aforementioned shortcomings is by utilizing fine materials [3-6] and polymers [7-11]. The fine materials assist in modifications of the concrete microstructure, resulting in a least porosity and dense matrix [6]. However, the fine materials, in order to be effective, need to be added in relatively large amounts, in which the concrete will be more costly. On the other hand, polymers, unlike fine materials, can be used in small amounts to enhance the performance of cement paste, cement mortar and concrete products [7-11]. For this reason, different types of polymer additives in the field of concrete industries have been tried, such as; re-dispersible polymer powders, liquid resins, monomers and water-soluble polymers [7]. Among the water-soluble polymers, polyvinyl alcohol (PVA) has been introduced and exploited in the field of cement-based products [11-17].

Reviewing the research work regarding the fresh properties, studies have indicated that up to a certain limit, the incorporation of PVA has positive influences on concrete workability and water retention ability $[12,14,16]$. However, the influences of PVA towards the hardened properties of cement-based products have been found to have inconsistent results. In some research work, it was concluded that the addition of PVA is accompanied with an improvement of the mix compressive strength [15, 18-19]. According to Mannan et al. [18] and Kou and Poon [19], treatment of oil palm shell aggregate and recycled aggregate with PVA showed an improvement in strength performance of concrete specimens. However, Kim et al. [12] reported that PVA can reduce the compressive strength of cement mortar as it increases the air voids content. Regarding the flexural strength, Allahverdi et al. [11] reported that with a lower w/c ratio, the cement pastes modified with PVA showed a slight decrease in flexural strength. Kim et al. [12] concluded that with the addition of PVA, no significant changes were observed in flexural strength of cement mortar samples. However, different results were also found in a previous study [20] in which the PVA modified cement mortar samples showed a noticeable increase in their flexural strength as compared with unmodified samples. For more details regarding the rule of PVA on cement-based products, we refer the researcher to recently published paper [13], where the state of the art review on this topic has been deeply discussed.

Due to the inconsistent findings and limited literature published about the influence of PVA on the properties of concrete, its characteristics behavior and performance still need to be thoroughly addressed. Beside that, since no research work (to the best knowledge of the author) has locally been reported until now, it is not clear whether or not the performance of concrete mixes containing PVA is still the same when locally available materials are used. Therefore, more laboratory work, in this regard, are crucial to drawing reliable conclusions. In this paper, the goal was to experimentally investigating the role of two compositional parameters - PVA dosage and strength grade (i.e., w/c ratio) - of concrete mixes in their fresh and hardened properties. These mixes, which comprised locally sourced building materials, were examined in the fresh state using setting time and workability tests, and in the hardened state by performing compressive strength, splitting tensile strength and total water absorption tests.

\section{EXPERIMENTAL PROGRAM}

\subsection{MATERIALS}

In this research a locally available type I cement, commercially known "Crista", was used. It satisfies Iraqi specification (IQS) No.5/1984 [21]. Crushed coarse aggregate of $20 \mathrm{~mm}$ size and 2.63 specific gravity was used. The fine aggregate (natural sand) with a maximum grain size of $4.75 \mathrm{~mm}$ and a specific gravity of 2.60 was used. Both the fine and coarse aggregates satisfy IQS No.45/1984 [22]. A solution of PVA was prepared by watery dissolving the polymer; $60 \mathrm{~g}$ of PVA was boiled in $1000 \mathrm{ml}$ water. The solution was then subjected to heating over a period of 10 hours with continuous stirring in a temperature of $100 \mathrm{C}$, and it was then kept overnight at ambient temperature in the lab. 


\section{AL-QADISIYAH JOURNAL FOR ENGINEERING SCIENCES}

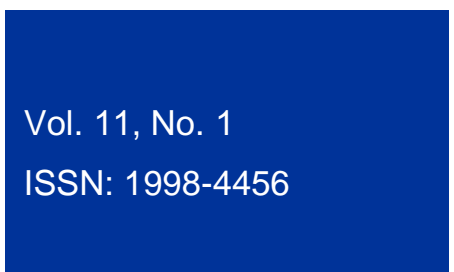

\subsection{PROPORTIONING}

In this study, a series of concrete mixes using three different $w / c$ ratios of $0.6,0.5$ and 0.4 were carried out. They were designated MixL, MixM and MixH for relatively low, medium and high compressive strengths, respectively. The constituent materials of the prepared mixes were initially chosen with the aid of British mix design procedure [23]. However, the actual constituents (as will be explained later in sectios 3.1 and 3.3) depended on (1) the amount of the mixing water that allowed the slump values of control mixes to vary between $30-60 \mathrm{~mm}$, and (2) the amount of fine aggregate that was adjusted to keep the mass of coarse aggregate constant in all prepared mixes. The mix proportions (per cubic metre) were presented in Table 1. PVA dosages were 1, 2, 3 and $4 \%$ by mass of cement. PVA solution had been replaced by an equivalent amount of mixing water and mixed with it before they were added to the remaining ingredients in the mixer.

Table 1. Constituent materials of the tested concrete mixes, $\mathrm{kg} / \mathrm{m}^{3}$

\begin{tabular}{|c|c|c|c|c|c|c|c|}
\hline $\begin{array}{c}\text { Mix } \\
\text { designation }\end{array}$ & $(w+P V A) / c^{*}$ & Cement & $\begin{array}{c}\text { Fine } \\
\text { aggregate }\end{array}$ & $\begin{array}{c}\text { Coarse } \\
\text { aggregate }\end{array}$ & Water & PVA & $\begin{array}{c}\% \text { PVA by } \\
\text { cement weight }\end{array}$ \\
\hline MixOL & \multirow{5}{*}{0.6} & \multirow{5}{*}{335} & \multirow{5}{*}{760} & \multirow{5}{*}{1050} & 202.0 & 0.0 & 0 \\
\hline Mix1L & & & & & 198.7 & 3.4 & 1 \\
\hline Mix2L & & & & & 195.3 & 6.7 & 2 \\
\hline Mix3L & & & & & 192.0 & 10.1 & 3 \\
\hline Mix4L & & & & & $188.6^{`}$ & 13.4 & 4 \\
\hline Mix0M & \multirow{5}{*}{0.5} & \multirow{5}{*}{380} & \multirow{5}{*}{745} & \multirow{5}{*}{1050} & 190.0 & 0 & 0 \\
\hline Mix1M & & & & & 186.2 & 3.8 & 1 \\
\hline Mix2M & & & & & 182.4 & 7.6 & 2 \\
\hline Mix3M & & & & & 178.6 & 11.4 & 3 \\
\hline Mix4M & & & & & 174.8 & 15.2 & 4 \\
\hline $\mathrm{MixOH}$ & \multirow{5}{*}{0.4} & \multirow{5}{*}{445} & \multirow{5}{*}{730} & \multirow{5}{*}{1050} & 178.0 & 0.0 & 0 \\
\hline Mix1H & & & & & 173.6 & 4.5 & 1 \\
\hline Mix2H & & & & & 169.1 & 8.9 & 2 \\
\hline Mix3H & & & & & 164.7 & 13.4 & 3 \\
\hline Mix4H & & & & & 160.2 & 17.8 & 4 \\
\hline
\end{tabular}

$(\mathrm{W}+\mathrm{PVA}) / \mathrm{c}^{*}$ : Figure in parenthesis refers to substitution of PVA by an equivalent amount of the mixing water such that $w / c$ ratio becomes $(w+P V A) / c$.

\subsection{TEST PROCEDURE}

In the present study, experimental tests for the fresh and hardened mixes were carried out, including: initial and final setting times, slump, compressive strength, splitting tensile strength and total water absorption. The initial and final setting time tests were conducted on cement pastes according to ASTM C191-82 [24]. The slump of fresh concrete was measured using the standard slump test apparatus according to ASTM C143 [25]. For each concrete mix, three cubes of $150 \mathrm{~mm}$ and six cylinders of $100 \times 200$ $\mathrm{mm}$ were cast to determine the compressive strength $\left(f_{c u}\right)$, splitting tensile strength $\left(f_{s t}\right)$, and total water absorption (TWA), respectively. All specimens were cast in steel moulds and then demolded after 24 hours 


\section{AL-QADISIYAH JOURNAL FOR ENGINEERING SCIENCES}

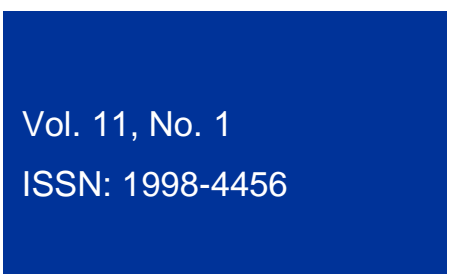

and cured in water until the age of 28 days. $f_{c u}, f_{s t}$ and TWA were measured according to B.S. 1881 [26], ASTM C496-86 [27] and ASTM C-642 [28], respectively.

\section{RESULTS AND DISCUSSION}

\subsection{WORKABILITY}

To investigate the effect of PVA on the workability of fresh concrete mixes, slump test was performed in this study. From an engineering perspective, water content is considered the most important parameter affecting the workability of fresh concrete. To take this issue into consideration, the amounts of water contents in the control mixes (MixOL, MixOM and $\mathrm{MixOH}$ ) were adjusted by performing trial mixes to maintain slump values in the range of $30-60 \mathrm{~mm}$. To get more precise results of the slump test, PVA solution was replaced by an equivalent amount of the water used in the mixes such that $\mathrm{w} / \mathrm{c}$ ratio was represented by $(\mathrm{w}+\mathrm{PVA}) / \mathrm{c}$. Another important parameter of the fresh concrete workability, which cannot be overlooked, is the volume fraction of coarse aggregate (CA). It forms more than $33 \%$ of the total mix volume. In order to eliminate any possible influence of this parameter on the fresh properties, CA amounts were kept constant for all prepared mixes.

The results of slump test of the present study have been presented in Table 2 and graphically plotted in Figures 1-2. Figure 1 shows that there is a significant improvement in the workability of fresh concrete for all produced mixes, regardless of the $\mathrm{mix} \mathrm{w} / \mathrm{c}$ ratio. Increasing PVA up to $4 \%$, increases the slump values, with respect to control mix, from 62 to $83 \mathrm{~mm}$, from 35 to $67 \mathrm{~mm}$ and from 41 to $85 \mathrm{~mm}$ for w/c ratios of $0.4,0.5$ and 0.6 respectively. As indicated in Figure 2, the maximum relative slump to the control mix (at $4 \%$ PVA) is about 148,191 and 207 for w/c ratios of $0.4,0.5$ and 0.6 respectively. As mentioned above, the workability of control mixes depended on trail mixes to reach the target slump range. This could explain the reason behind the difference in slump values of the control mixes prepared with the chosen w/c ratios.

The positive effect of PVA on the workability is in agreement with results of a study carried out by Allahverdi et al. [11] and Kim et al. [12]. The improved workability with the addition of PVA is very likely attributed to the enhancement of concrete matrix due to the "ball bearing" effect of the water-soluble polymer $[11,13]$. The other key reason behind that enhancement in fresh concrete workability could be the deflocculating influence of PVA on the cement particles in addition to its lubricating effect on the fine and coarse aggregates in the mix. Accordingly, it would be worthwhile to examine the role of PVA to be used as a water reducing admixture (plasticizer), which in turn, would result in decreasing water demands for a particular mix workability, and thereby, improving its strength.

Table 2. Slump test results of the fresh mixes

\begin{tabular}{|c|c|c|c|c|c|}
\hline \multicolumn{2}{|c|}{$\mathrm{w} / \mathrm{c}=0.6$} & \multicolumn{2}{c|}{$\mathrm{w} / \mathrm{c}=0.5$} & \multicolumn{2}{c|}{$\mathrm{w} / \mathrm{c}=0.4$} \\
\hline $\begin{array}{c}\text { Mix } \\
\text { designation }\end{array}$ & $\begin{array}{c}\text { Slump } \\
\mathrm{mm}\end{array}$ & $\begin{array}{c}\text { Mix } \\
\text { designation }\end{array}$ & $\begin{array}{c}\text { Slump } \\
\mathrm{mm}\end{array}$ & $\begin{array}{c}\text { Mix } \\
\text { designation }\end{array}$ & $\begin{array}{c}\text { Slump } \\
\mathrm{mm}\end{array}$ \\
\hline Mix0L & 41 & Mix0M & 35 & Mix0H & 62 \\
\hline Mix1L & 51 & Mix1M & 40 & Mix1H & 76 \\
\hline Mix2L & 68 & Mix2M & 56 & Mix2H & 84 \\
\hline Mix3L & 82 & Mix3M & 63 & Mix3H & 80 \\
\hline Mix4L & 85 & Mix4M & 67 & Mix4H & 83 \\
\hline
\end{tabular}




\section{AL-QADISIYAH JOURNAL FOR ENGINEERING SCIENCES}

Vol. 11 , No. 1

ISSN: $1998-4456$

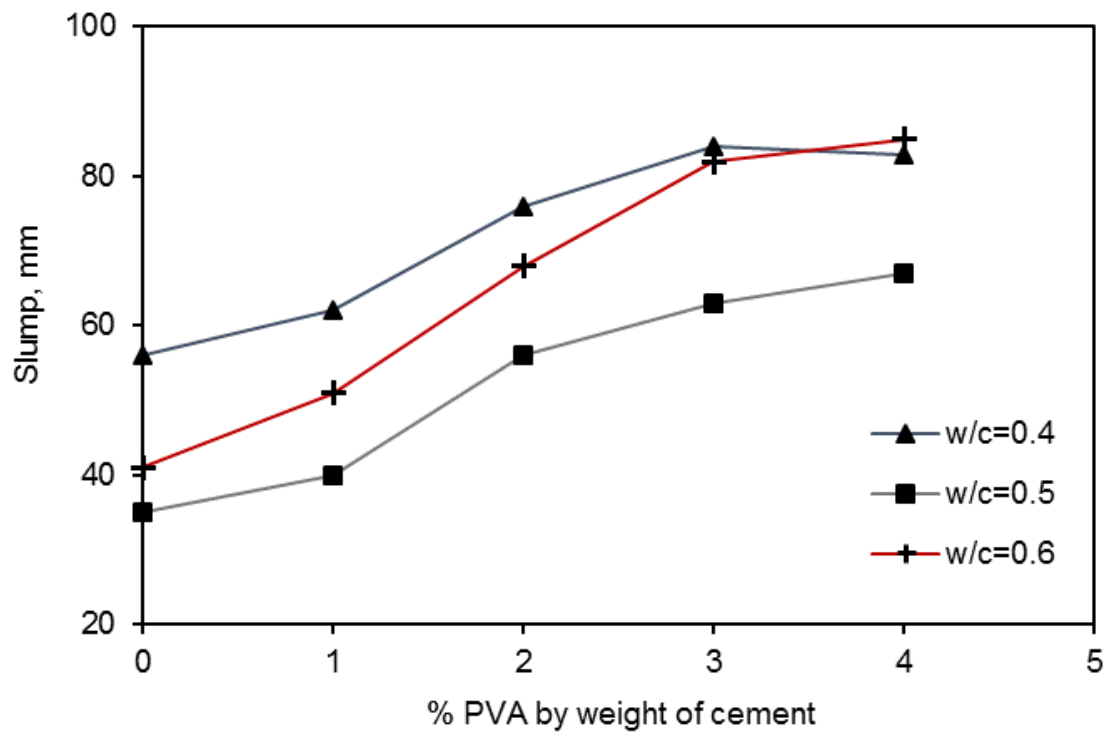

Figure 1: Slump test of the fresh mixes versus PVA dosages at different w/c ratios

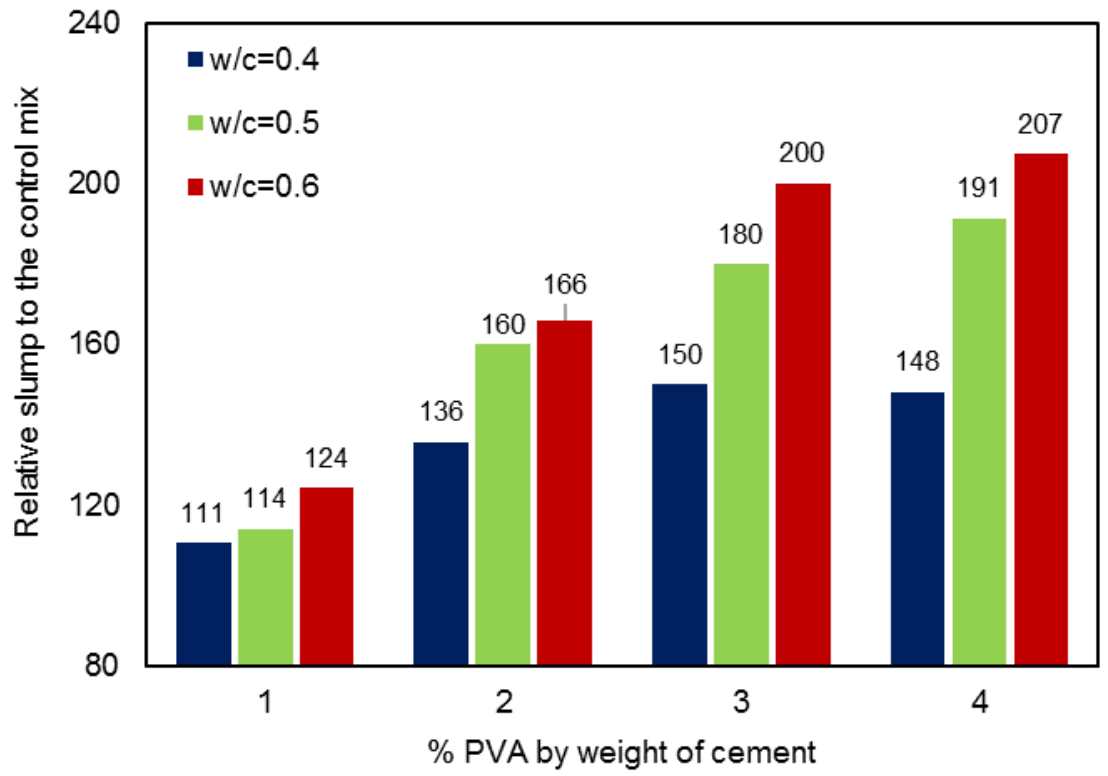

Figure 2: Relative slump to the control mix at different PVA dosages and w/c ratios

\subsection{SETTING TIME}

The results of the initial and final setting time of the produced mixes using Vicat apparatus [24] are given in Table 3 and Figures 3-4. Apparently from Figure 3, both setting times increase when up to $2 \%$ PVA is added, and thereafter decrease. With respect to the control mix, they increase from 74 to 89 min and from 267 to $300 \mathrm{~min}$, corresponding to an increase of $20 \%$ and $12 \%$, respectively, when up to $2 \%$ PVA is used. However, above this percentage, the initial setting time of cement paste remains longer than that of the control paste. As clearly seen in Figure 4, the relative initial and final setting time reach about $116 \%$ and 


\section{AL-QADISIYAH JOURNAL FOR ENGINEERING SCIENCES}

Vol. 11, No. 1

ISSN: $1998-4456$

$98 \%$ of the control mix, respectively, when 4\% PVA is added. A possible justification for that increase in the setting time is that the microstructure of cement paste matrix could be altered with the presence of PVA, which acts as an agent for inhibiting the hydration of cement particles.

It is worth emphasising that the workability and setting time of concrete can be considered as the two key issues influencing its fresh state and hardened state as well [23]. This is of prime importance when planning to cast a concrete mix in a hot weather. Without paying attention to this issue, concrete will practically experience a difficulty in its construction process such as, transporting, handling, placing and finishing. Based on the above results, the use of PVA in concrete industries, particularly in the climates that are characterized by long hot and dry summers, is expected to offer a simultaneous potential in workability (as plasticizer) and in setting time (as a retarder admixture). Thus, the influences of aforementioned circumstances on the construction process of fresh concrete can be mitigated. In this regard, it is, however, necessary to use an optimum dosage of PVA because its high amount (as will be seen later), might result in negative consequences on the concrete strength.

Table 3. Initial and final setting time test results

\begin{tabular}{|c|c|c|}
\hline \multirow{2}{*}{$\begin{array}{c}\text { \% PVA } \\
\text { by cement weight }\end{array}$} & Setting time, min. \\
\cline { 2 - 3 } & Initial & Final \\
\hline 0 & 74 & 267 \\
\hline 1 & 83 & 285 \\
\hline 2 & 89 & 300 \\
\hline 3 & 87 & 269 \\
\hline 4 & 86 & 261 \\
\hline
\end{tabular}

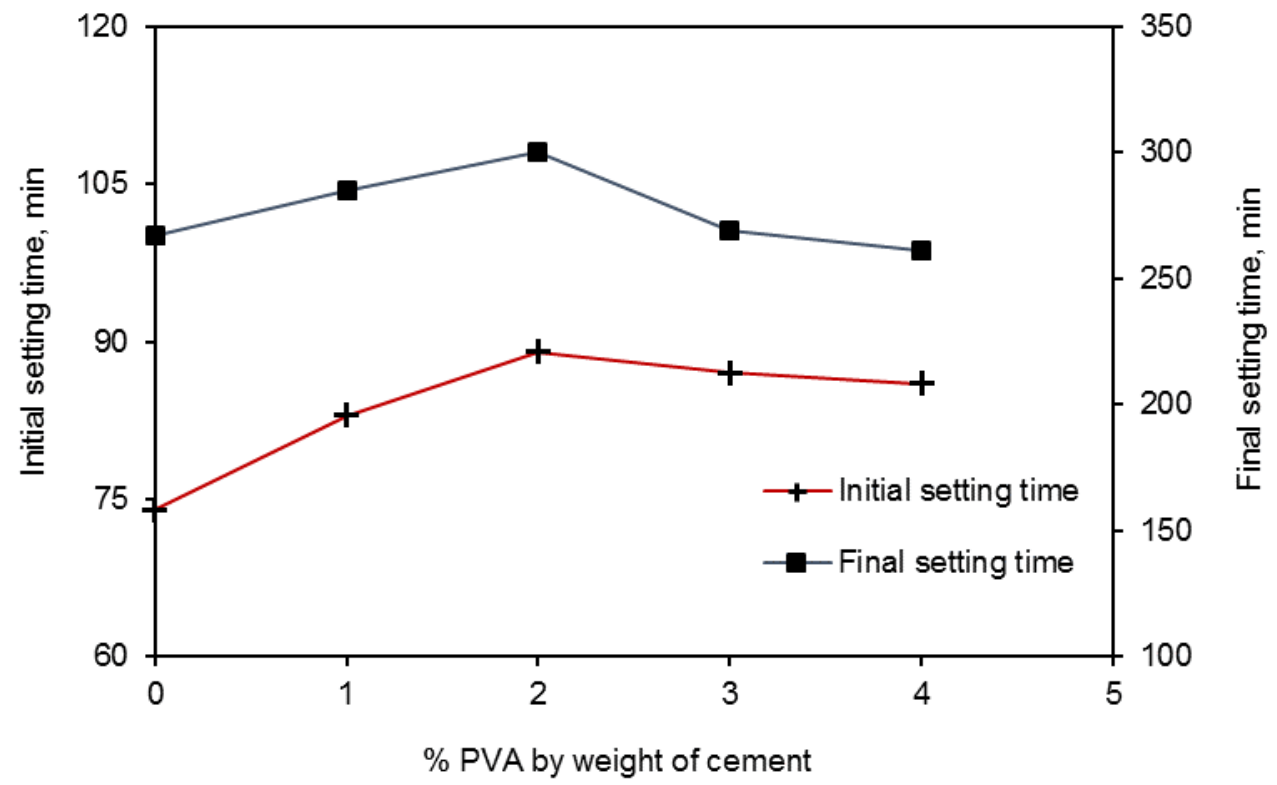

Figure 3: Initial and final setting times of cement pastes at different PVA dosages 

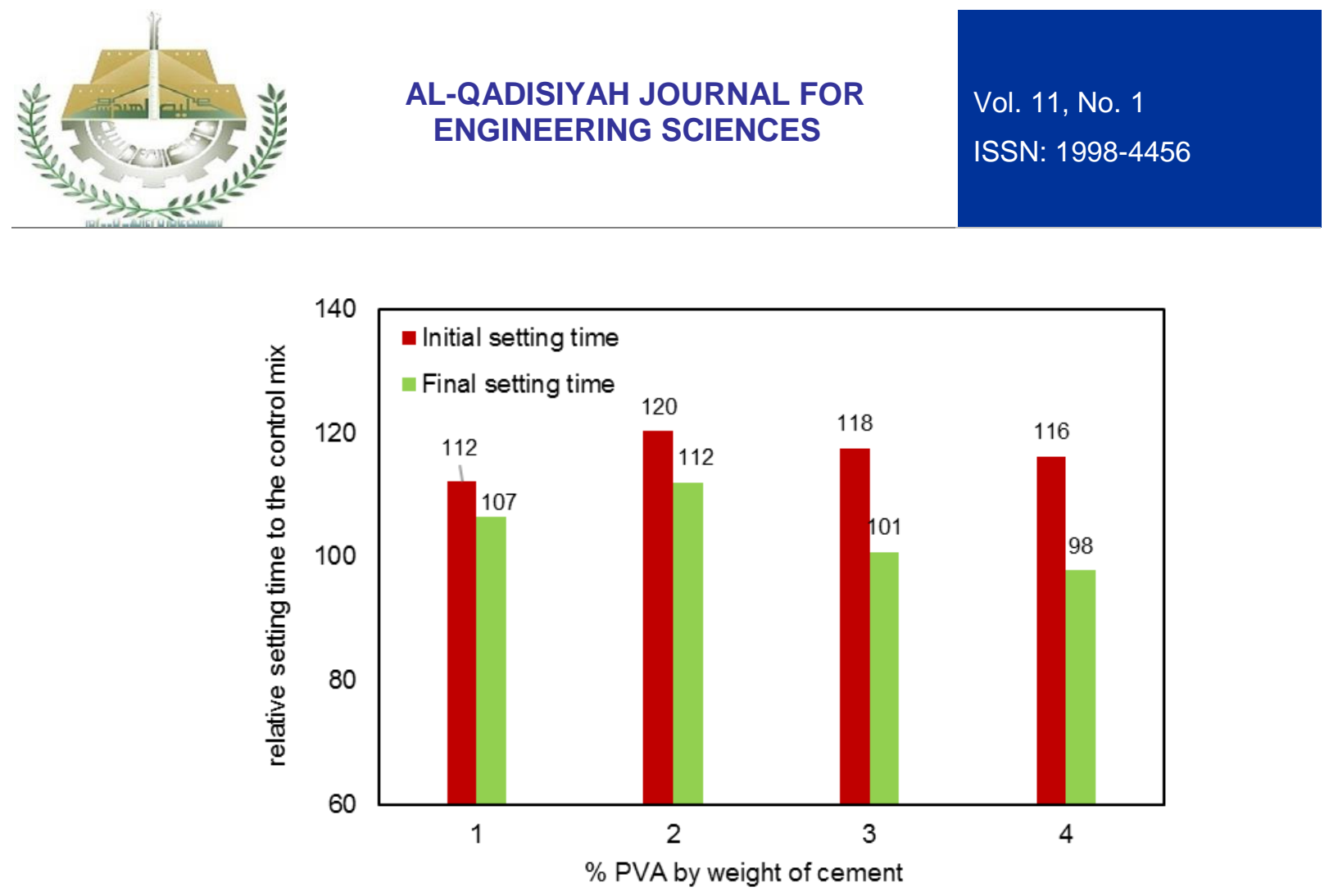

Figure 4: Relative setting time to the control mix at different PVA dosages

\subsection{COMPRESSIVE STRENGTH}

The compressive strength $\left(f_{c u}\right)$ is considered to be the most important property of concrete structures that provides an indication of their general performance [23]. This property is primerly determined by the water to cement ratio $(\mathrm{w} / \mathrm{c})$ under particular parameters. In addition to $\mathrm{w} / \mathrm{c}$ ratio, concrete mixes are also influenced by the amounts of coarse aggregate $(C A)$ as it typically occupies more than a third of the concrete volume. Consequently, changes in CA contents can affect the workability and strength as well. That is, for this reason, the masses of CA in all produced mixes were kept constant (see Table 2). This will exclude any possible effect of this ingredient material on the concrete strength, allowing the $\mathrm{w} / \mathrm{c}$ ratio and PVA dosage to be the most important mix parameters controlling its strength. Keeping the amount of CA constant, the fine aggregate (FA) was adjusted in all produced mixes such that the total mix volume worked out to be $1 \mathrm{~m}^{3}$, accordingly.

The results of compressive strength $\left(f_{c u}\right)$ at the age of 28 days are shown in Table 4 and plotted for all $\mathrm{w} / \mathrm{c}$ ratios in Figures 5-6. It is indicated that, $f_{c u}$ seems to be dominated by the amounts of PVA in the mix and the $\mathrm{w} / \mathrm{c}$ ratios. With the high w/c ratio (i.e. 0.6 ), $f_{c u}$ increases moderately (about $11 \%$ ) when up to $2 \%$ PVA is used (Mix2L) and thereafter decreases, but it remains approximately the same as the control mix at the maximum PVA dosage. For the mix with $0.5 \mathrm{w} / \mathrm{c}, f_{c u}$ increases marginally $(3 \%)$ when up to $2 \%$ PVA is used, and then decreases, as clearly seen in Figure 6 . The increase in $f_{c u}$ with the addition of PVA could be due to the chemical interaction between the PVA and cement particles that results in improving mix microstructure and formation some new compounds in the cement matrix [12]. From the other side, in the mixes with a w/c ratio of 0.4 (Mix $1 \mathrm{H}-\mathrm{Mix} 2 \mathrm{H})$, which possess the lowest $\mathrm{w} / \mathrm{c}$ ratio among the produced mixes, the addition of PVA does not provide improvements in the compressive strength, but instead, it decreases the strength when more than $2 \%$ is added. At $4 \%$ PVA (Mix $4 \mathrm{H}), f_{c u}$ registered about $90 \%$ of the control mix (Figure 6). 
AL-QADISIYAH JOURNAL FOR ENGINEERING SCIENCES
Vol. 11 , No. 1

ISSN: $1998-4456$

Table 4. Hardened properties test results

\begin{tabular}{|c|c|c|c|}
\hline $\begin{array}{c}\text { Mix } \\
\text { designation }\end{array}$ & $\begin{array}{c}f_{c u} \\
\text { MPa }\end{array}$ & $\begin{array}{c}f_{s t} \\
\text { MPa }\end{array}$ & $\begin{array}{c}\text { TWA } \\
\%\end{array}$ \\
\hline Mix0L & 24.5 & 2.25 & 5.10 \\
\hline Mix1L & 26.8 & 2.53 & 4.78 \\
\hline Mix2L & 27.2 & 2.47 & 4.05 \\
\hline Mix3L & 26.0 & 2.35 & 3.60 \\
\hline Mix4L & 24.8 & 2.28 & 3.38 \\
\hline Mix0M & 31.4 & 3.41 & 4.35 \\
\hline Mix1M & 31.1 & 3.56 & 4.17 \\
\hline Mix2M & 30.4 & 3.59 & 3.75 \\
\hline Mix3M & 30.1 & 3.26 & 3.23 \\
\hline Mix4M & 29.5 & 3.05 & 3.15 \\
\hline Mix0H & 42.4 & 4.55 & 3.44 \\
\hline Mix1H & 42.0 & 4.61 & 3.35 \\
\hline Mix2H & 41.7 & 4.46 & 3.23 \\
\hline Mix3H & 38.6 & 4.28 & 2.78 \\
\hline Mix4H & 38.0 & 3.72 & 2.63 \\
\hline
\end{tabular}

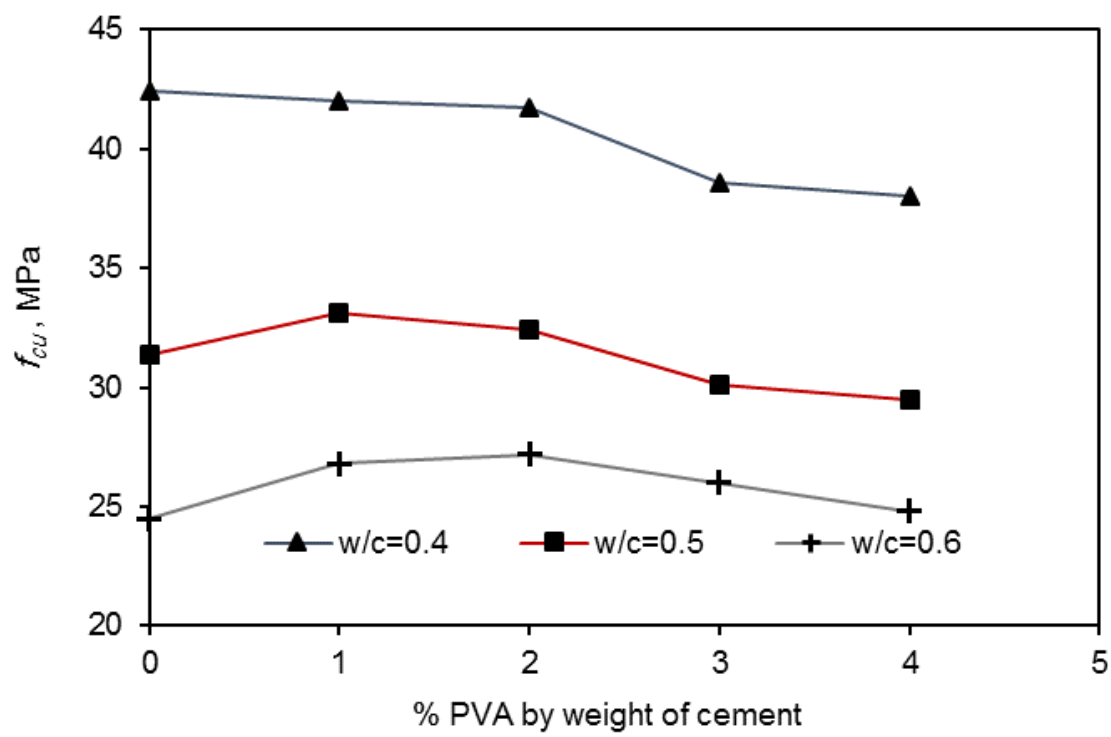

Figure 5: Compressive strength versus PVA dosages at different $w / c$ ratios 


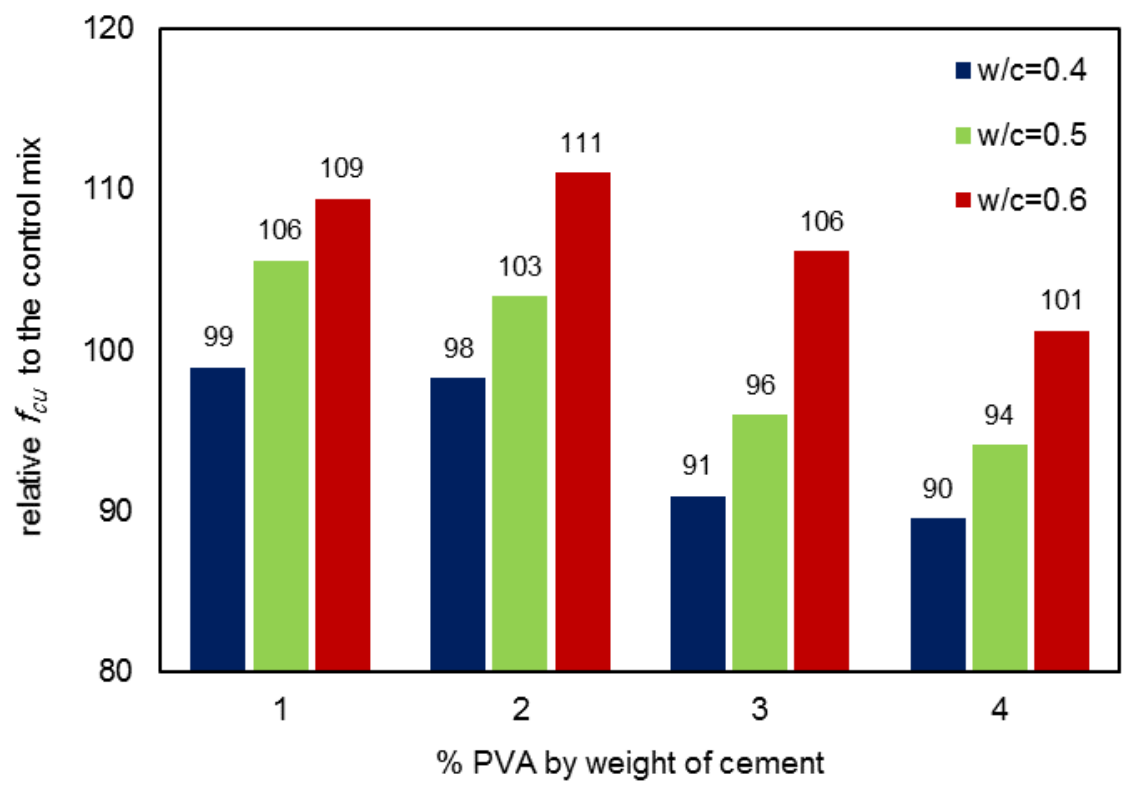

Figure 6: Relative $f_{c u}$ to the control mix at different PVA dosages and $\mathrm{w} / \mathrm{c}$ ratios

\subsection{SPLITTING TENSILE STRENGTH}

The splitting tensile strength $\left(f_{s t}\right)$ of the prepared mixes (using cylinders of $100 \times 200 \mathrm{~mm}$ ) is indicated in Table 4 and Figures 7-8. The influence of PVA on $f_{s t}$ is found to be almost similar to that of compressive strength. With $\mathrm{w} / \mathrm{c}$ ratio of 0.6 , the presence of PVA in the concrete mixes demonstrates an increase of about $12 \%$ in their $f_{s t}$ when up to $2 \%$ PVA is added (Mix $1 \mathrm{~L}$ and Mix2L), then it decreases as PVA percentage increases. The improved microstructure due to the formation of new compounds in the cement matrix could be the reason behind that enhancement in $f_{s t}[12]$. However, in $3 \%$ and $4 \%$ PVA (Mix $3 \mathrm{~L}$ and Mix4L), less enhancement in $f_{s t}$ is observed.

Apparently from Figure 8, $f_{s t}$ is found to have a marginal increase (about $5 \%$ ) in the mixes with 0.5 $\mathrm{w} / \mathrm{c}$ ratio, but it has no changes in that of $0.4 \mathrm{w} / \mathrm{c}$ ratio when up to $2 \%$ PVA is added. Beyond this percentage, the produced mixes suffer from a reduction in their tensile strength, and this reduction is more pronounced when using 4\% PVA (Mix4H). This could be justified by incomplete hydrolysis of PVA due to the relatively lower amounts of provided water $(160 \mathrm{~kg})$, which is exhausted in the workability and hydration of the relatively high amount of cement $(445 \mathrm{~kg})$ in Mix4H. For comparison, Allahverdi et al [11] reported that $f_{s t}$ of cement paste mixes with $0.3 \mathrm{w} / \mathrm{c}$ ratio was found to be two folds of the reference mix when about $2 \%$ PVA was used. 


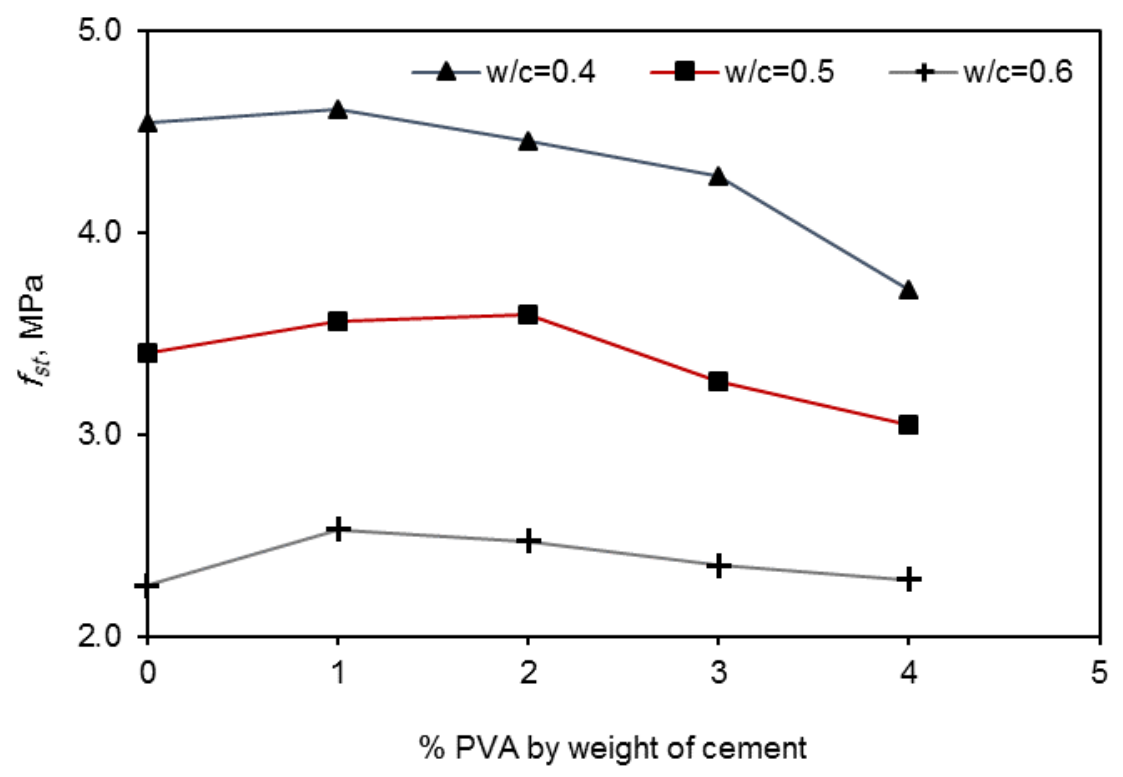

Figure 7:Splitting tensile strength versus PVA dosages at different w/c ratios

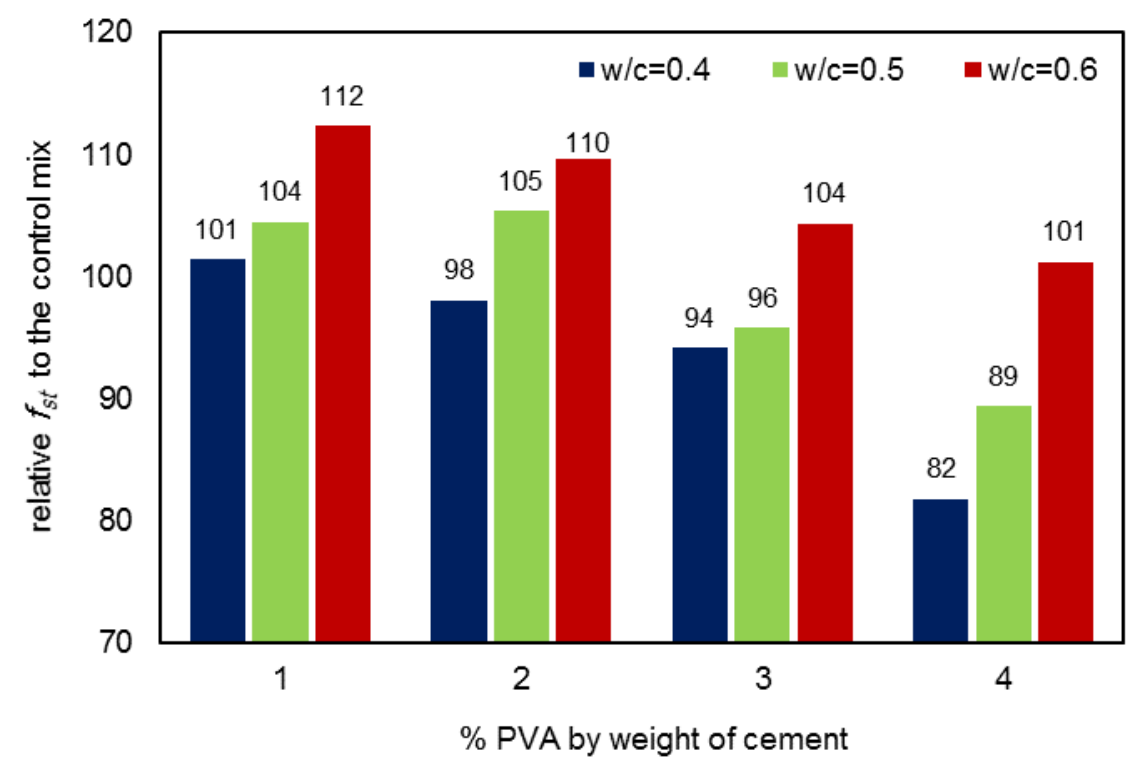

Figure 8: Relative $f_{s t}$ to the reference mix at different PVA dosages and $\mathrm{w} / \mathrm{c}$ ratios 


\section{AL-QADISIYAH JOURNAL FOR ENGINEERING SCIENCES}

Vol. 11, No. 1

ISSN: $1998-4456$

\subsection{TOTAL WATER ABSORPTION}

From an engineering point of view, porosity or water absorption is one of the important key parameters From an engineering point of view, porosity or water absorption is one of the important key parameters controlling concrete durability. In other words, any reduction in the concrete porosity can yield to an improvement in its durability performance [23]. From the test results presented in Figures 9-10, it can be noticed that with the increase in PVA contents, there is a considerable reduction in the total water absorption (TWA) of the concrete mixes for all w/c ratios. As clearly seen in Figure 10, TWA of concrete specimens with $4 \%$ of PVA can be reduced by approximately $24 \%, 28 \%$ and $34 \%$ for $0.4,0.5$ and $0.6 \mathrm{w} / \mathrm{c}$ ratios, respectively, in comparison with the control mixes. Here, it is, however, worth mentioning that while $4 \%$ of PVA is the optimum amount for reducing TWA, the concrete specimens, in term of strength, reach their best performance when up to $2 \%$ PVA is used. For comparison, the results of TWA in this study are in agreement with the findings reported in [11-12].

The positive influences of PVA on TWA are very likely related to the improved concrete microstructure, which in turn is significantly affected by the interfacial transition zone (ITZ) between the cement paste and aggregate [16]. The ITZ of concrete mixes treated with PVA becomes denser and more uniform as compared with the untreated mixes [13]. Accordingly, promising findings in term of durability performance of concrete specimens subjected to different curing conditions can be expected. In this regard, an extensive experimental study by the author is ongoing.

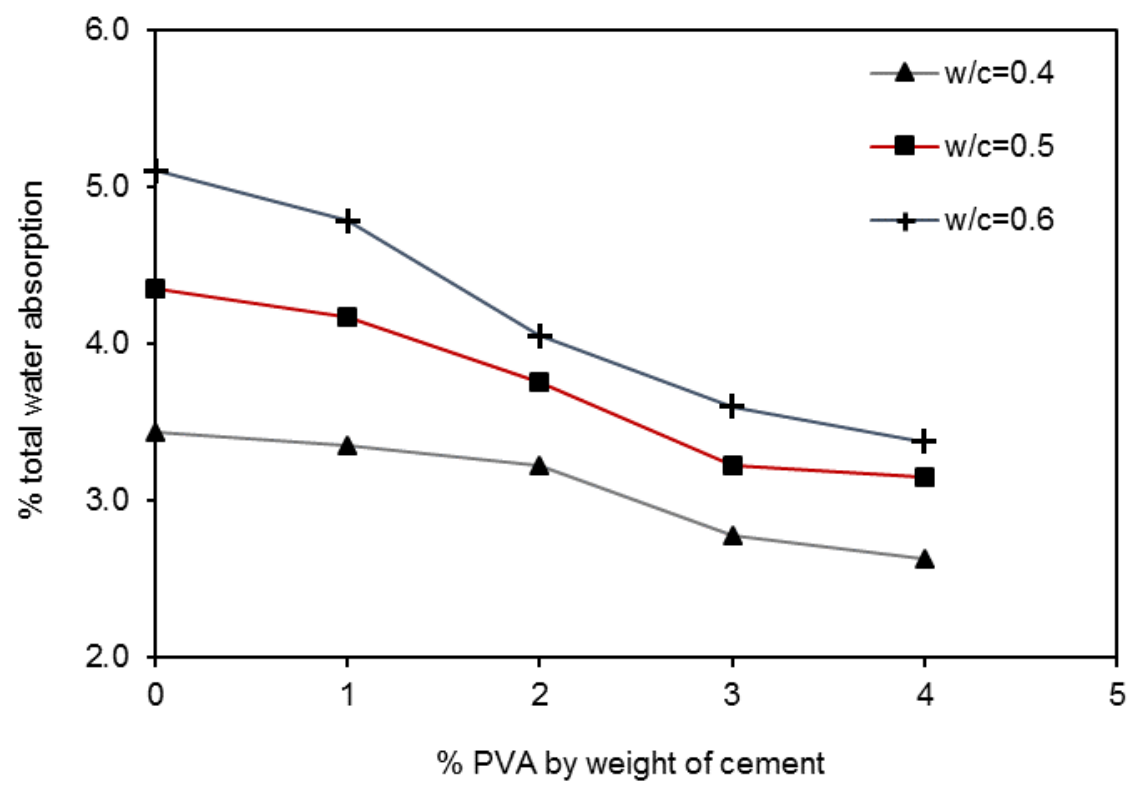

Figure 9: Total water absorption versus PVA dosages at different w/c ratios 


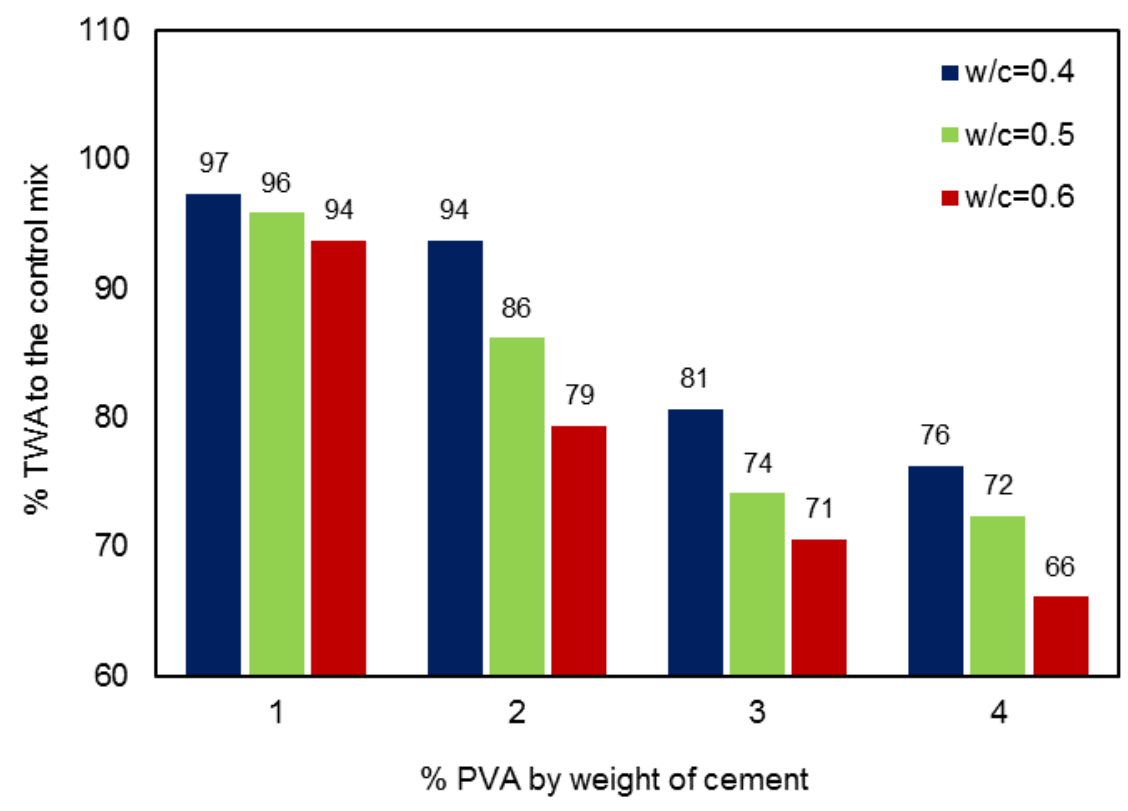

Figure 10: Relative TWA to the control mix at different PVA dosages and w/c ratios

\section{CONCLUSIONS}

The main findings of the presented study indicate that PVA modified concrete mixes are accompanied with improvements in their fresh and hardened properties, alike. These can be summarized as follows:

1. The initial and final setting time of the cement pastes increase when up to $2 \%$ PVA is added, and thereafter decrease. However, PVA is comparatively more effective in increasing the initial than final setting time.

2. There is a significant improvement in concrete workability with increasing the dosage of PVA, irrespective of the mix w/c ratio, although the improvement is less pronounced in the mixes with a relatively low $w / c$ ratio.

3. The compressive $\left(f_{c u}\right)$ and splitting tensile $\left(f_{s t}\right)$ strengths of concrete are controlled by the amounts of PVA in the mix and the w/c ratios. With the high and moderate w/c ratios, they increase when up to $2 \%$ PVA is added. However, with the low w/c, PVA does not provide any improvement in the strength, but instead, it decreases it when more than $2 \%$ is used.

4. The porosity of concrete specimens is considrably reduced with the addition of PVA at all w/c ratios. The higher the PVA content the lower is the total water absorption. Here, it is interesting to mention that while $2 \%$ of PVA is the optimum amount for both compressive and splitting tensile strength, concrete specimens in term of porosity as well as workability reach the best performance when PVA is increased to $4 \%$. 


\section{ACKNOWLEDGMENT}

The author is thankful to Mr. Alshemary (senior lecturer in the Chemical Engineering Department - the University of Al-Qadisiyah) for preparing the PVA used in this research work. The author is also grateful to the technical staff of concrete laboratory of Engineering Consultant Bureau in the College of Engineering the University of Al-Qadisiyah- for their assistance during the testing period.

\section{REFERENCES}

1. Patzák, B. and Bittnar, Z. Modeling of fresh concrete flow. Computers and Structures, 87, 2009, pp. 962-969.

2. Karihaloo, B.L. Fracture Mechanics and Structural Concrete. UK: Addison Wesley Longman, 1995.

3. Dinakar, P., Reddy, M.K. and Sharma, M. Behaviour of self-compacting concrete using Portland pozzolana cement with different levels of fly ash. Materials and Design, 46, 2013. pp. 609-616.

4. Domone, P.L. and Illston, J. Construction materials: Their nature and behaviour. New York, USA: Spon Press, 2010.

5. Dinakar, P., Sethy, K.P. and Sahoo, U.C. Design of self-compacting concrete with ground granulated blast furnace slag. Materials and Design, 43, 2013. pp. 161-169.

6. Siddique, R., Khan, M. I. Supplementary Cementing Materials: Silica Fume. Engineering Materials, Ch:2. Springer-Verlag Berlin Heidelberg, 2011, pp. 67-119.

7. Eren, F., Gödek, E., Keskinates, M., Felekog`lu, KM, Felekog`lu, B. Effects of latex modification on fresh state consistency, short term strength and long term transport properties of cement mortars, Constr. Build. Mater. 133, 2016, 226-233.

8. Soni, E.K. and Joshi, Y.P. Performance Analysis of Styrene Butadiene Rubber-Latex on Cement Concrete Mixes, Int. J. Eng. Res. Appl. 4 (3), 2014, 838-844.

9. Wang, R., Lackner, R., P.M. Wang, Effect of styrene-butadiene rubber latex on mechanical properties of cementitious materials highlighted by means of nanoindentation, Strain 47 (2), 2011, 117-126.

10. Aggarwal, L.K., Thapliyal, P.C., Karade, S.R. Properties of polymer-modified mortars using epoxy and acrylic emulsions, Constr. Build. Mater. 21 (2), 2007, 379-383.

11. Allahverdi, A., Kianpur, K., Moghbeli, M.R. Effect of polyvinyl alcohol on flexural strength and some important physical properties of Portland cement paste, Iran. J. Mater. Sci. Eng. 7 (1), 2010, 1-6.

12. Kim J, Robertson RE, Naaman AE. Structure and properties of poly (vinyl alcohol)-modified mortar and concrete. Cem Concr Res ,1999, ;29 (3): 407-15.

13. Thong, C, Teo, D Ng, C. Application of polyvinyl alcohol (PVA) in cement-based composite materials: A review of its engineering properties and microstructure behavior. Constr. Build. Mater. 107, 2016, 172-180.

14. Ohama Y. Polymer-based admixtures. Cem Concr Res 1998;20(2-3):189-212.

15. Singh NB, Rai S. Effect of polyvinyl alcohol on the hydration of cement with rice husk ash. Cem Concr Res $2001 ; 31(2):$ 239-43.

16. Kim J, Robertson RE. Effects of polyvinyl alcohol on aggregate-paste bond strength and the interfacial transition zone. Adv Cem Based Mater 1998 ; 8 (2): 66-76.

17. Santos RS, Rodrigues FA, Segre N, Joekes I. Macro-defect free cements influence of polyvinyl alcohol, cement type, and silica fume. Cem Concr Res 1999; 29 (5): 747-51.

18. Mannan, M.A., Alexander, J., Ganapathy, C., Teo, D.C.L. Quality improvement of oil palm shell (OPS) as coarse aggregate in lightweight concrete, Build. Environ. 41 (9), 2006, 1239-1242. 


\section{AL-QADISIYAH JOURNAL FOR ENGINEERING SCIENCES}

Vol. 11, No. 1

ISSN: $1998-4456$

19. Kou, S.C. Poon, C.S. Properties of concrete prepared with PVA-impregnated recycled concrete aggregates, Cem. Concr. Compos. 32 (8), 2010, 649-654.

20. Knapen, E., Van Gemert, D. Water-soluble polymers for modification of cement mortars, Int. Symp. Polym. Concr., Guimarães, Portugal, 2006, 85-93.

21. Iraqi Organization of Standards, IOS 5: 1984, for Portland Cement.

22. Iraqi Organization of Standards, IOS 45: 1984, for Aggregate.

23. Neville, A.M. Properties of concrete. 4th ed. UK: Longman Scientific Group Ltd. 1995.

24. ASTM C191-92, American Standard Test Method, 1993.

25. American Society for Testing and Materials, C143-89a, Standard Test Method for Slump of Hydraulic Cement Concrete, Annual Book of ASTM Standards, (04) (02), 1989, pp.85-86.

26. British Standard Institution, Method for Determination of Compressive Strength of Concrete Cubes, B.S. 1881: Part 116: 1983, 3 pp.

27. American Society for Testing and Materials, C496-86, Standard Test Method for Splitting Tensile Strength of Cylindrical Concrete Specimens, Annual Book of ASTM Standards, Vol.04.02, 1989, pp.259-262. 